\title{
SURFACE CRACKING AND INTERFACE REACTION ASSOCIATED DELAMINATION FAILURE OF THERMAL AND ENVIRONMENTAL BARRIER COATINGS
}

\author{
Dongming Zhu, Sung R. Choi, Jeffrey I. Eldridge, Kang N. Lee and Robert A. Miller \\ NASA John H. Glenn Research Center \\ 21000 Brookpark Road, Cleveland, OH 44135
}

\begin{abstract}
In this paper, surface cracking and interface reactions of a BSAS coating and a multi-layer $\mathrm{ZrO}_{2}-8 \mathrm{wt} \% \mathrm{Y}_{2} \mathrm{O}_{3}$ and mullite/BSAS/Si thermal and environmental barrier coating system on $\mathrm{SiC} / \mathrm{SiC}$ ceramic matrix composites were characterized after long-term combined laser thermal gradient and furnace cyclic tests in a water vapor containing environment. The surface cracking was analyzed based on the coating thermal gradient sintering behavior and thermal expansion mismatch stress characteristics under the thermal cyclic conditions. The interface reactions, which were largely enhanced by the coating surface cracking in the water vapor environment, were investigated in detail, and the reaction phases were identified for the coating system after the longterm exposure. The accelerated coating delamination failure was attributed to the increased delamination driving force under the thermal gradient cyclic loading and the reduced interface adhesion due to the detrimental interface reactions.
\end{abstract}

\section{INTRODUCTION}

Thermal and environmental barrier coatings (T/EBCs) will play a critical role in future advanced gas turbine engines to protect $\mathrm{Si}$-based engine components in the harsh combustion environments. In order to develop high performance ceramic coating systems, advanced laser based high-heat-flux approaches have been established to test coating systems under the simulated engine heat flux condition [1,2]. The laser thermal gradient test rigs can establish a required thermal gradient across the coating system, so the coating can be evaluated at very high surface temperatures while the coating/substrate interface and the substrate can still be maintained below a safe temperature limit. The laser thermal gradient approaches have been demonstrated in evaluating cyclic and sintering behavior of thermal/environmental barrier coatings on $\mathrm{SiC} / \mathrm{SiC}$ substrates $[3,4]$.

The purpose of this study is to investigate coating cracking and interface chemical reactions induced failure of typical thermal and environmental barrier coating system on $\mathrm{SiC} / \mathrm{SiC}$ ceramic matrix composite $(\mathrm{CMC})$ substrates under laser thermal gradient cyclic test conditions. The coating surface and delamination cracking was analyzed based on the coating thermal gradient sintering behavior and thermal expansion mismatch stress characteristics under the thermal cyclic conditions. The thermal strain/stress characteristics under large thermal gradients were also described. The accelerated coating failure was discussed based on the delamination driving force

This is a preprint or reprint of a paper intended for presentation at a conference. Because changes may be made before formal publication, this is made available with the understanding that it will not be cited or reproduced without the permission of the author. 
under the thermal gradient cyclic loading and the interface degradation due to the BSAS phase chemical stability and reactions in high temperature water vapor environment.

\section{EXPERIMENTAL MEHOD AND MATERIALS}

The laser high-heat-flux based technique was employed to test a barium-strontiumaluminosilicate (BSAS) and a multi-layered $\mathrm{ZrO}_{2}-8 \mathrm{wt} \% \mathrm{Y}_{2} \mathrm{O}_{3}$ and $\mathrm{BSAS}+$ mullite mixture/Si $\mathrm{TBC} / \mathrm{EBC}$ system on $\mathrm{SiC} / \mathrm{SiC} \mathrm{CMC}$ substrates under thermal gradient cyclic conditions. The thermal gradient cyclic testing of the ceramic coatings was carried out using a $3.0 \mathrm{~kW} \mathrm{CO}$ laser (wavelength $10.6 \mu \mathrm{m}$ ) high-heat flux rig. The general test approaches have been described elsewhere [1-4]. The surface test temperature was at approximately at $482^{\circ} \mathrm{C}$, and interface temperature was at $1300^{\circ} \mathrm{C}$. The coatings specimens were also subject to alternating the laser thermal gradient cycling test in air and the furnace thermal cycling tests in a $90 \%$ water vapor environment at $1300^{\circ} \mathrm{C}$ (every 50 hours). The thermal cyclic tests were conducted using 1 hour hot time temperature cycles, with $3 \mathrm{~min}$ cooling between each cycle to ensure that the test specimens were cooled below $100^{\circ} \mathrm{C}$. The coatings were tested up to total 400,1 hour cycles. The coating surface cracking and interface reactions of the coating systems were characterized after the testing using a scanning electron microscope (SEM) equipped with an energy dispersive spectroscopy (EDS) System.

\section{RESULTS AND DISCUSSION}

Fig. 1 shows SEM microstructures the BSAS/Si environmental barrier coating after laser thermal gradient cyclic testing. It can be seen from Fig. 1 (a) that the BSAS coating was first decomposed and precipitated a lower silicon $(\mathrm{Si})$ containing phase, with the matrix being a high $\mathrm{Si}$ containing BSAS. As the coating was further cyclically tested at surface temperature of $1482 \mathrm{C}$, 4 the BSAS matrix was melted because of the formation of the higher $\mathrm{Si}$ and lower melting point BSAS. The surface cracking was also observed after coating melting and glass phase formation.
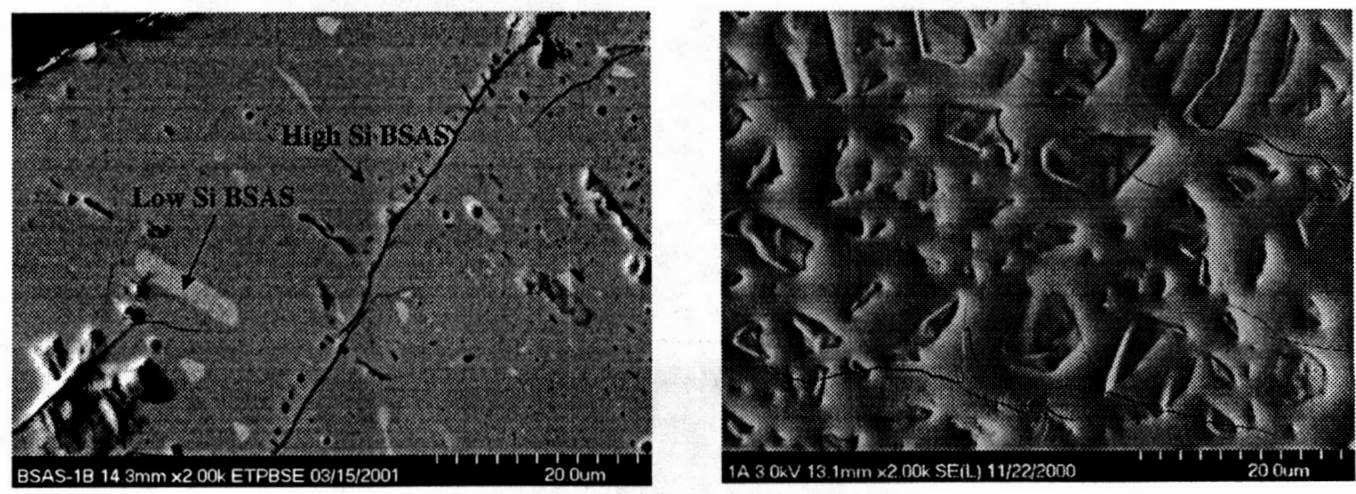

Fig. 1 (a) The BSAS coating was decomposed into low Si (bright second) and high Si (dark matrix) phases during initial laser thermal cyclic testing. (b) The higher Si phase became the glass phase and surface cracks were formed after 100 hour cyclic testing at the surface temperature of $1482^{\circ} \mathrm{C}$. 
Fig. 2 shows a SEM cross-section micrograph of the BSAS coating after 100 hour laser thermal gradient cycling test. The interface reactions between the Si bond coat and BSAS coating resulted in a dark reaction layer with the layer thickness of 30-40 microns. The EDS analysis has shown that this BSAS region has very high $\mathrm{Si}$ concentrations due to the $\mathrm{Si}$ diffusion from the $\mathrm{Si}$ bond coat into the BSAS. The high Si concentration BSAS phase was also decomposed into mullite phase (very dark needle-shaped phase) within the high Si BSAS reaction region. Although the coating interface melting was not observed under the $1300^{\circ} \mathrm{C}$ interface temperature of the thermal gradient testing for 100 hours, the high Si concentration BSAS reaction layer has been reported to facilitate the coating melting and the glass phase formation under the uniform temperature furnace testing in a water vapor environment at higher temperatures [5].

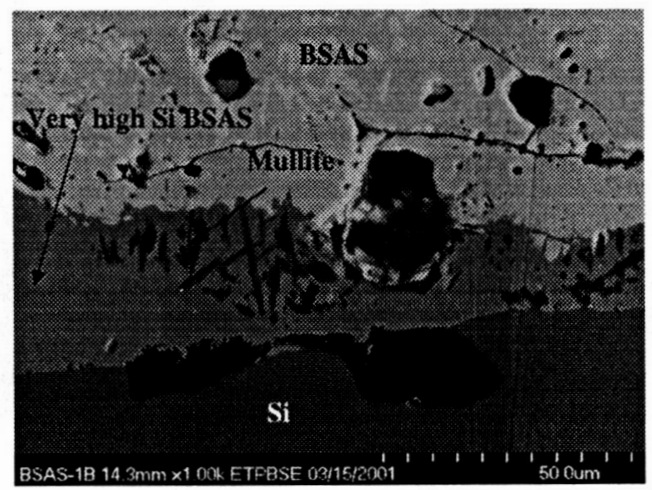

Fig. 2 SEM cross-section micrograph of the BSAS coating after 100 hour laser thermal gradient cycling test. The interface reactions resulted in a dark reaction BSAS layer with high $\mathrm{Si}$ concentrations. The mullite phase (very dark needle-shaped phase) precipitation was also found within the high Si reaction BSAS region.

Fig. 3 shows cross-section micrographs and compositional maps of the $\mathrm{ZrO}_{2}$ $8 \mathrm{wt} \% \mathrm{Y}_{2} \mathrm{O}_{3} / \mathrm{BSAS}+$ mullite mixture/Si on a $\mathrm{SiC} / \mathrm{SiC}$ ceramic matrix composite substrate, after 100 hours testing in a combined alternating laser thermal gradient cyclic and furnace water vapor exposure cyclic testing. It can be seen that substantial thermal gradient induced coating surface wedge-shape cracking has occurred and the resulting delamination was observed for the coating specimen. As shown in Fig. 3, significant interface reactions within the mullite+BSAS EBC layer occurred. The reaction affected zone can be as thick as 30 to 40 microns, especially near the interface and the BSAS phase (bright phase) regions. The reactions between mullite and BSAS phases were also noticed with a typical reaction layer thickness of 2-5 microns. However, the interdiffusion of $\mathrm{Ba}$ and $\mathrm{Al}$ between the mullite and BSAS can occur at a much greater distance, as indicated by the EDS composition maps in Fig. 3 (d) and (e). The reactions were further enhanced by the surface crack penetrations into the EBC layer which allowed the water vapor fast access to the coating at the EBC/Si interface. The accelerated coating damage under the thermal gradient cyclic testing combined with the furnace water vapor testing was attributed to the increased delamination driving force under the thermal gradient cyclic loading and the reduced interface adhesion due to the detrimental interface reactions $[4,6]$. 
The coating surface cracking is largely due to ceramic top coat sintering and thermal expansion mismatch, especially under the large thermal gradient conditions. As can be seen in Fig. 4 , with a relatively thick, higher thermal expansion $\mathrm{ZrO}_{2}-\mathrm{Y}_{2} \mathrm{O}_{3}$ TBC layer on mullite-BSAS EBC and $\mathrm{CMC}$ substrates, the coating surface cracking and delamination driving force can increase significantly, based on a thermal gradient testing delamination model proposed in the literature [7]. The significantly larger thermal stresses generated under thermal gradients will also accelerate the coating delamination under the thermal cyclic conditions.

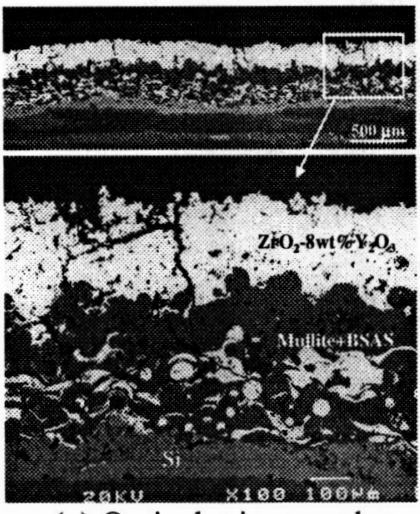

(a) Optical micrograph

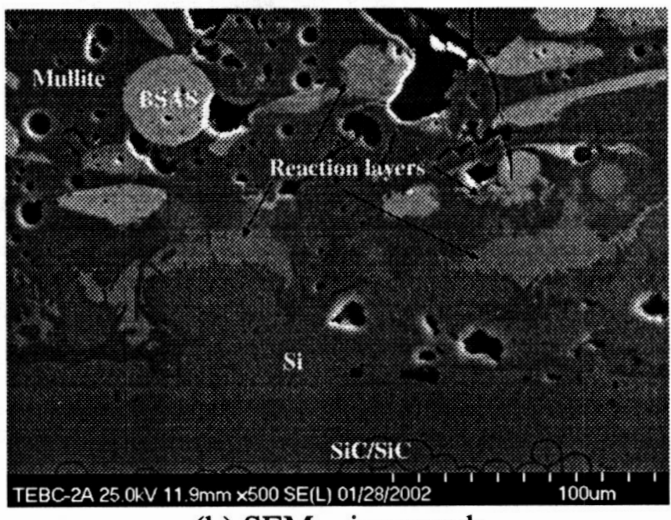

(b) SEM micrograph

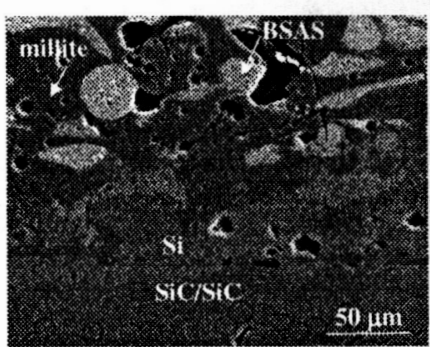

(c) SEM image



(f) Si Map

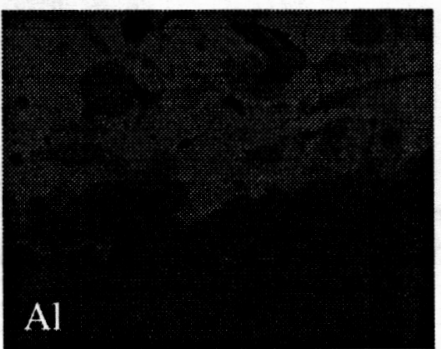

(d) Al Map

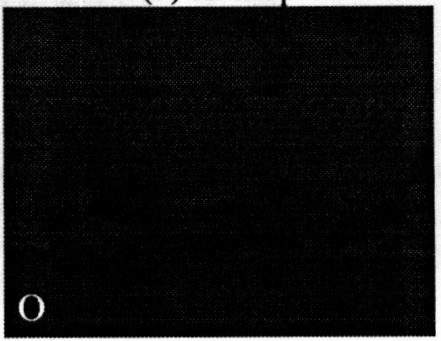

(g) O Map

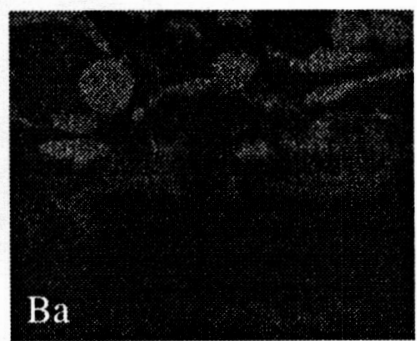

(e) Ba Map

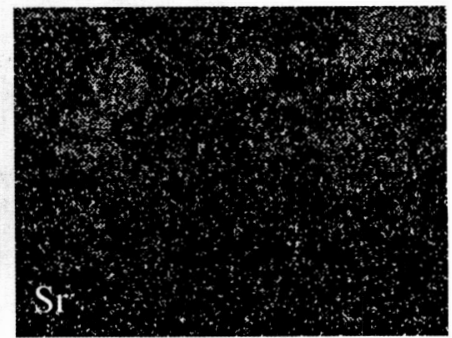

(h) Sr Map

Fig. 3 SEM images and EDS element composition maps of the $\mathrm{ZrO}_{2}-8 \mathrm{wt} \% \mathrm{Y}_{2} \mathrm{O}_{3} / \mathrm{BSAS}+$ mullite mixture/Si on $\mathrm{SiC} / \mathrm{SiC}$ ceramic matrix composite substrates after laser testing, showing significant interface reactions between BSAS and bond coat Si layer, and the BSAS and mullite. (a) and (b) Optical and SEM micrographs of the coating after 100 hours testing, showing the surface cracking and interface reactions; and (c) to (h) SEM cross-section 
micrograph and the corresponding EDS elemental maps for the coating systems near the interface.

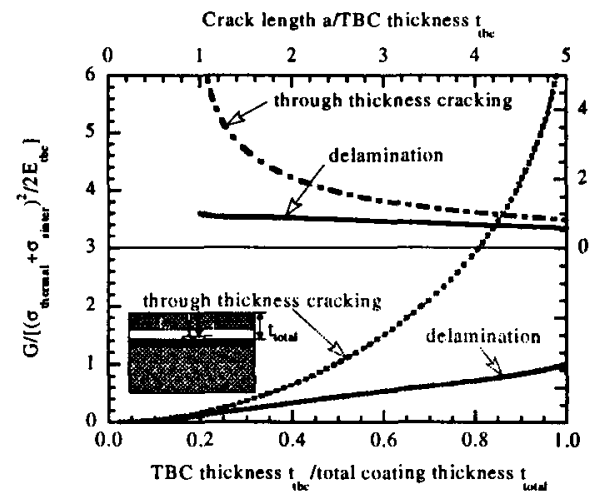

(a)

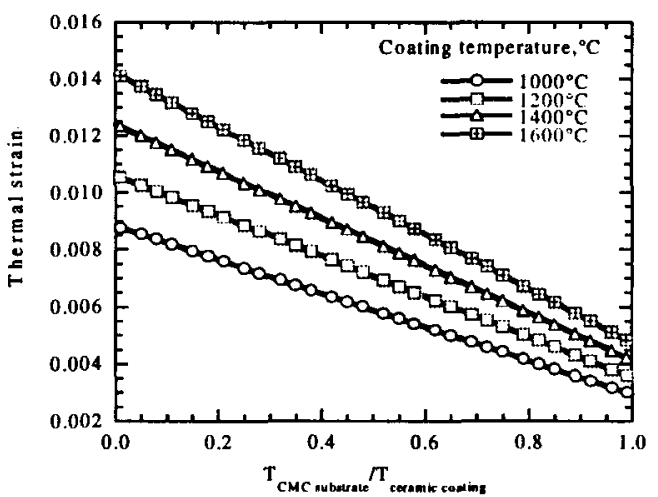

(b)

Fig. 4 (a) $\mathrm{ZrO}_{2}-\mathrm{Y}_{2} \mathrm{O}_{3}$ TBC layer on mullite-BSAS EBC and CMC substrates, the coating surface cracking and delamination energy release rates can increase significantly with a relatively thick, and larger thermal expansion $\mathrm{ZrO}_{2}-\mathrm{Y}_{2} \mathrm{O}_{3}$ TBC layer on mullite-BSAS EBC on CMC substrates. (b) The significantly larger thermal stresses/strains will be generated with increasing the thermal gradients (the temperature difference between the ceramic coating and the substrates).

Fig. 5 shows the SEM cross-section micrographs of the $\mathrm{ZrO}_{2}-8 \mathrm{wt} \% \mathrm{Y}_{2} \mathrm{O}_{3} / \mathrm{BSAS}+$ mullite mixture/Si on a $\mathrm{SiC} / \mathrm{SiC}$ ceramic matrix composite substrate, after 400 hours of testing in the combined laser thermal gradient and furnace water vapor cyclic testing. Extensive coating delamination and some spallation were observed during the testing. From Fig 5 (a) and (b), it can be seen that, in addition to the more significant reactions between the EBC mullite, BSAS and Si bond coat, large interfacial pores developed due to the water vapor attack through the vertical cracks in the EBC coatings. From Fig. 5 (c) and (d), it can also be seen that a low melting point eutectic phase around the BSAS, $\mathrm{Si}$, and mullite interfaces formed. For the top $\mathrm{ZrO}_{2}-\mathrm{Y}_{2} \mathrm{O}_{3}$ coating side, no obvious reactions were found between mullite and $\mathrm{ZrO}_{2}-8 \mathrm{wt} \% \mathrm{Y}_{2} \mathrm{O}_{3}$ coatings after the 400 hours combined laser and furnace water vapor thermal cycling test. 




(a)

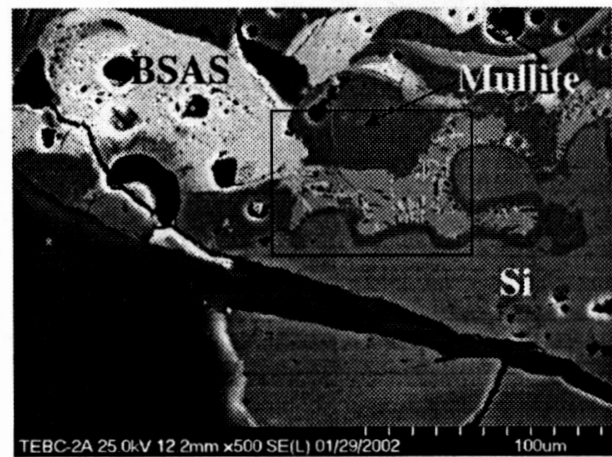

(c)



(b)

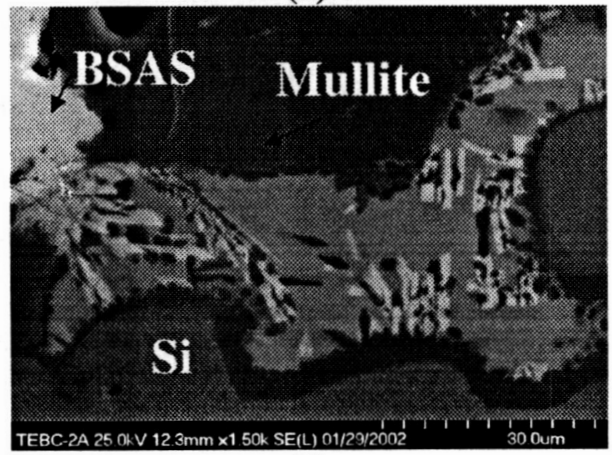

(d)

Fig. 5 SEM cross-section micrographs of the $\mathrm{ZrO}_{2}-8 \mathrm{wt} \% \mathrm{Y}_{2} \mathrm{O}_{3} / \mathrm{BSAS}+$ mullite mixture/Si on a $\mathrm{SiC} / \mathrm{SiC}$ ceramic matrix composite substrate, after total 400 hours testing in the combined laser thermal gradient and furnace water vapor cyclic testing. (a) Significant interfacial pore formation due to the water vapor attack through the vertical cracks under the thermal gradient cycling conditions. (b) Low melting eutectic phase was also observed near the BSAS-mullite-Si interfaces after the testing.

\section{CONCLUSIONS}

A laser heat-flux thermal gradient test approach has been used to investigate the interface reactions and failure of plasma-sprayed BSAS and $\mathrm{ZrO}_{2}-8 \mathrm{wt} \% \mathrm{Y}_{2} \mathrm{O}_{3} / \mathrm{BSAS}+$ mullite/Si coatings on $\mathrm{SiC} / \mathrm{SiC}$ ceramic matrix composites under thermal gradient cyclic conditions. The failure of the coating system can be characterized as wedge-shaped surface coating cracking, surface crackingenhanced coating delamination and interface debonding and spallation under the thermal cyclic conditions. Significant BSAS phase related chemical reactions were observed due to its low temperature stability and high diffusion activity. The BSAS coatings were found to melt at even relatively low temperatures $\left(1300-1482^{\circ} \mathrm{C}\right)$ because of the formation of higher $\mathrm{Si}$ content, and low melting-point phases, either at the surface due to its high temperature decomposition into high $\mathrm{Si}$ containing matrix phase with low Si BSAS precipitates, or near the interface when reacted with $\mathrm{Si}$ bond coat. The accelerated coating delamination failure was attributed to the increased delamination driving force under the thermal gradient cyclic loading and the reduced interface adhesion due to the detrimental interface reactions. 


\section{ACKNOWLEDGMENTS}

This work was supported by NASA Ultra-Efficient Engine Technology (UEET) Program. The authors are grateful to George W. Leissler and Terry R. McCue, QSS group at NASA Glenn Research Center for their assistance in the preparation of plasma-sprayed TBC/EBC coatings, and the SEM analysis, respectively.

\section{REFERENCES}

[1] D. Zhu and R. A. Miller, "Thermal Conductivity and Elastic Modulus Evolution of Thermal Barrier Coatings Under High Heat Flux Conditions," NASA Glenn Research Center, Cleveland, Ohio, NASA TM-209069, April 1999. Journal of Thermal Spray Technology, vol. 9, pp. 175-180, 2000

[2] D. Zhu, N. P. Bansal, K. N. Lee, and R. A. Miller, "Thermal Conductivity of Ceramic Thermal Barrier and Environmental Barrier Coating Materials," NASA Glenn Research Center, Cleveland NASA TM-211122, September 2001.

[3] D. Zhu, K. N. Lee, and R. A. Miller, "Thermal Conductivity and Thermal Gradient Cyclic Behavior of Refractory Silicate Coatings on SiC/SiC Ceramic Matrix Composites," Ceram. Eng. Sci. Proc., vol. 22, pp. 443-452, 2001.

[4] D. Zhu, K. N. Lee, and R. A. Miller, "Sintering and Cyclic Failure Mechanisms of MultiLayered Thermal and Environmental Barrier Coating Systems under High Thermal Gradient Test Conditions," Ceram. Eng. Sci. Proc., vol. 23, pp. 505-516, 2002.

[5] K.N. Lee, D.S. Fox, J.I. Eldridge, D. Zhu, R.C. Robinson, N.P. Bansal, and R.A. Miller, "Upper Temperature Limit of Environmental Barrier Coatings Based on Mullite and BSAS," NASA TM-2002-211372.

[6] Dongming Zhu, Kang N. Lee and Robert A. Miller, "Thermal Gradient Cyclic Behavior of Thermal/Environmental Barrier Coating System on SiC/SiC Ceramic Matrix Composites," in Proceedings of ASME Turbo Expo 2002, June 3-6, 2002, ASME Paper GT-2002-30632, Amsterdam, The Netherlands.

[7] J. H. Hutchinson and A. G. Evens, "On the delamination of thermal barrier coatings in a thermal gradient," Surface and Coatings Technology, vol. 149, 149 (2002), pp. 179-184, 2002. 